\title{
In Silico Molecular Docking Studies of Lichen Metabolites against Cyclooxygenase-2 Enzyme
}

\author{
Mohammad Firoz Khan", Sabreena AleemNabila1, Ridwan Bin Rashid ${ }^{2}$, Mohammad Sharifur \\ Rahman $^{3}$, Abu Asad Chowdhury ${ }^{3}$ and Mohammad Abdur Rashid ${ }^{3}$ \\ ${ }^{1}$ Department of Pharmacy, State University of Bangladesh, Dhaka- 1205, Bangladesh \\ ${ }^{2}$ Department of Microbiology, University of Dhaka, Dhaka- 1000, Bangladesh \\ ${ }^{3}$ Department of Pharmaceutical Chemistry, Faculty of Pharmacy, University of Dhaka, Dhaka- 1000, Bangladesh
}

Received: March 12, 2015; Accepted: April 15, 2015; Published (Web): July 21, 2015

\begin{abstract}
Cyclooxygenase-2 (COX-2) is an inducible enzyme that causes inflammation. COX-2 inhibitors are clinically effective anti-inflammatory agents with less gastrointestinal and renal toxicities. However, they lack anti-thrombotic activity and hence lead to increased incidences of adverse cardiovascular thrombotic events, including myocardial infarction. Therefore, there is still need to develop COX-2 inhibitors with better therapeutic effects and tolerability. The aim of the present study is to explore the anti-inflammatory activity of five lichen metabolites by conducting virtual screenings. In this regard, molecular docking simulations were carried out for the lichen metabolites namely atranorin, diffractic acid, lecanoric acid, salazinic acid and usnic acid with human COX-2 enzyme and the docked results were compared with the standard reference ligands (Celecoxib and Rofecoxib). Among all the docked ligands, the lecanoric acid demonstrated best binding affinity $-9.83 \mathrm{kcal} / \mathrm{mol}$ followed by atranorin $(-8.7 \mathrm{kcal} / \mathrm{mol})$ and diffractic acid $(-8.6 \mathrm{kcal} / \mathrm{mol})$ which are comparable to the reference ligands celecoxib $(-12.3 \mathrm{kcal} / \mathrm{mol})$ and rofecoxib $(-11.2 \mathrm{kcal} / \mathrm{mol})$. The salazinic acid and usnic acid has shown binding affinity of $-7.9 \mathrm{kcal} / \mathrm{mol}$ and -4.7 $\mathrm{kcal} / \mathrm{mol}$, respectively. Moreover, all the ligands except atranorin and diffractic acid satisfied Lipinski's rule of 5. From the docking results it was revealed that the lichen metabolites might have inhibitory activity against COX-2 enzyme, and are expected to be useful in conducting in vivo anti-inflammatory screenings on animal model which may lead to the development of more effective and potent new chemical entities with anti-inflammatory properties.
\end{abstract}

Key words: Lichen metabolites, Cyclooxygenase-2, Molecular docking, Anti-inflammatory.

\section{Introduction}

Cyclooxygenase (COX) is an endogenous enzyme involved in production of prostaglandins from arachidonic acid. There are two common isoforms of this enzyme such as COX-1 and COX-2. COX-1 is a constitutive enzyme whereas COX-2 is inducible and is expressed only after an inflammatory stimulus (Vane et al., 1998). COX-2 inhibitors are clinically effective anti-inflammatory agents with less gastrointestinal and renal toxicity. However, they lack anti-thrombotic activity and hence lead to increased incidences of adverse cardiovascular thrombotic events such as myocardial infarction. Therefore, there is still need to develop better therapeutic effect and tolerability of COX-2 inhibitors.
Lichens are symbiotic association of algae and fungi that occur in a wide variety of habitats and natural environmental conditions. A large number of lichen metabolites were reported to exhibit profound analgesic (Okuyama et al., 1995), antipyretic (Okuyama et al., 1995), anti-inflammatory (Vijayakumar et al., 2000), antimicrobial (Rashid et al., 2001) and anti-proliferative or cytotoxic activities (Eugenia et al., 1994; Oksanen 2006; Stocker-Worgotter 2008; Kristmundsdottir et al., 2005).

Rational drug design uses a variety of computational methods to identify novel compounds. One of those methods is molecular docking where interactions between protein receptors and ligands are predicted and analyzed (Akhila et al., 2012). In the present study efforts are made

Correspondence to: Mohammad Abdur Rashid; Tel.: 880-2-9661920, Ext. 8137; Fax: 880-2-9667222; E-mail: rashidma@du.ac.bd 
to identify novel natural lichen metabolites possessing anti-inflammatory activity using bioinformatics tools. In this regard, molecular docking simulations were carried out for the five lichen metabolites (atranorin, diffractic acid, lecanoric acid, salazinic acid and usnic acid) with human COX-2 enzyme.

\section{Methodology}

Preparation of target protein $X$-ray structure: The crystal structure of human COX-2 in complex with celecoxib (PDB code: 3LN1) (Wang et al., 2010) was selected as the protein target model in this virtual screening study. Water molecules, ligands and chain B, C and $\mathrm{D}$ were removed from the protein molecule using PyMOL (Schrödinger, version 1.7.4.4). Addition of hydrogen atoms to the protein was conducted by using
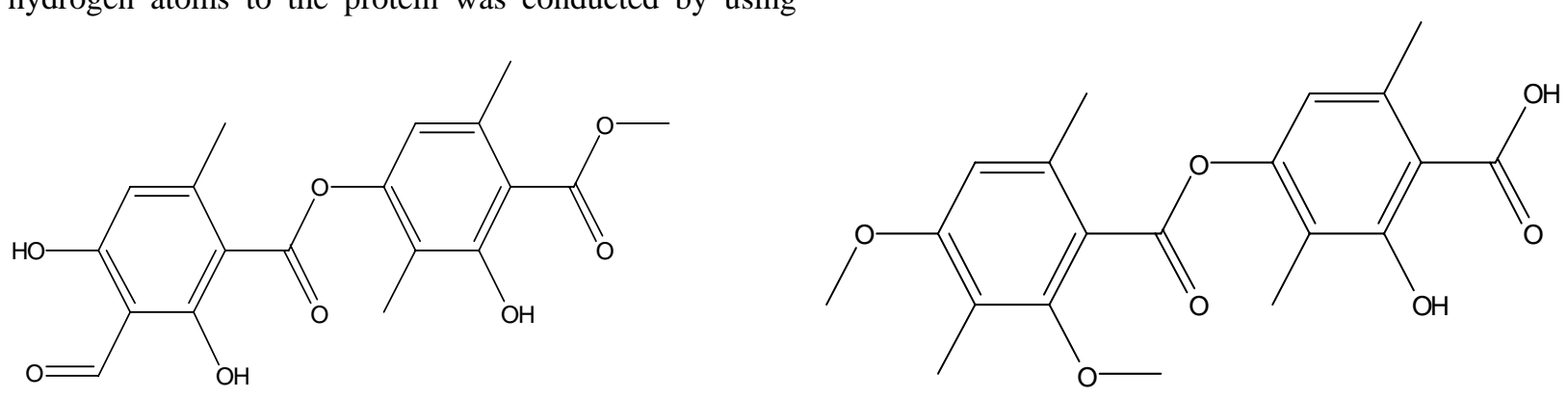

Atranorin

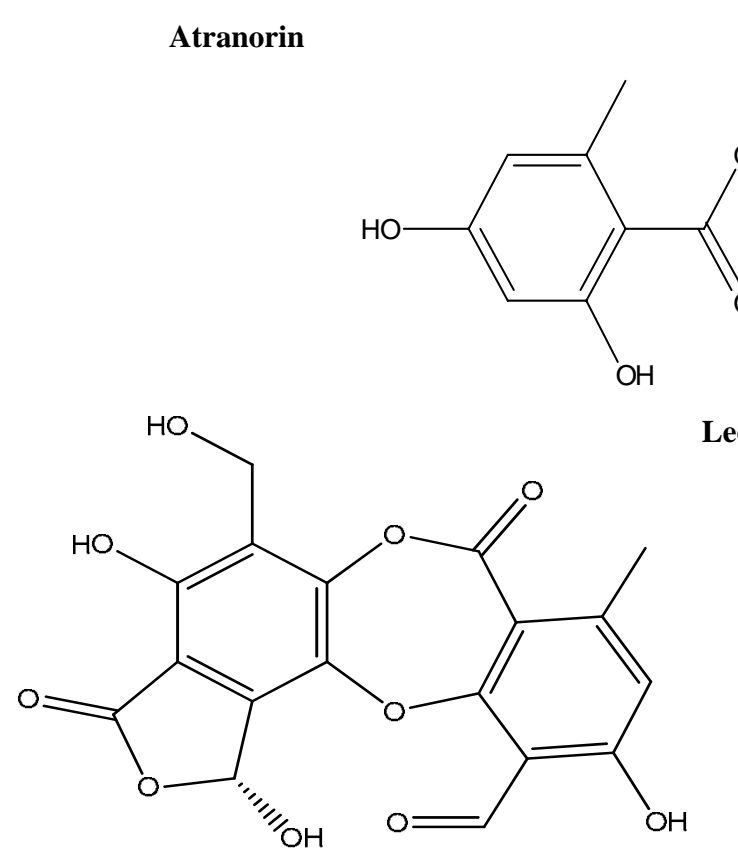

Salazinic acid
PyRx. Energy minimization was performed by applying MM/UFF level of theory in Gaussian 09 software (Frisch et al., 2010).

Preparation of ligands: The initial structure of the lichen metabolites namely Atranorin (CID 68066), Diffractic acid (CID 94870), Lecanoric acid (CID 99613), Salazinic Acid (CID 5320418) and Usnic acid (CID 5646) (Figure 1) were obtained from pubchem (https://pubchem. ncbi.nlm.nih.gov/search/). Molecular geometry optimization was then performed with the density functional theory at the B3LYP/Midix level using Gaussian 09 program (Frisch et al., 2010) to obtain the optimum geometry of the structures (Figure 2). The optimized structures of protein and ligands were then saved in PDB format for further analysis.

Diffractic acid
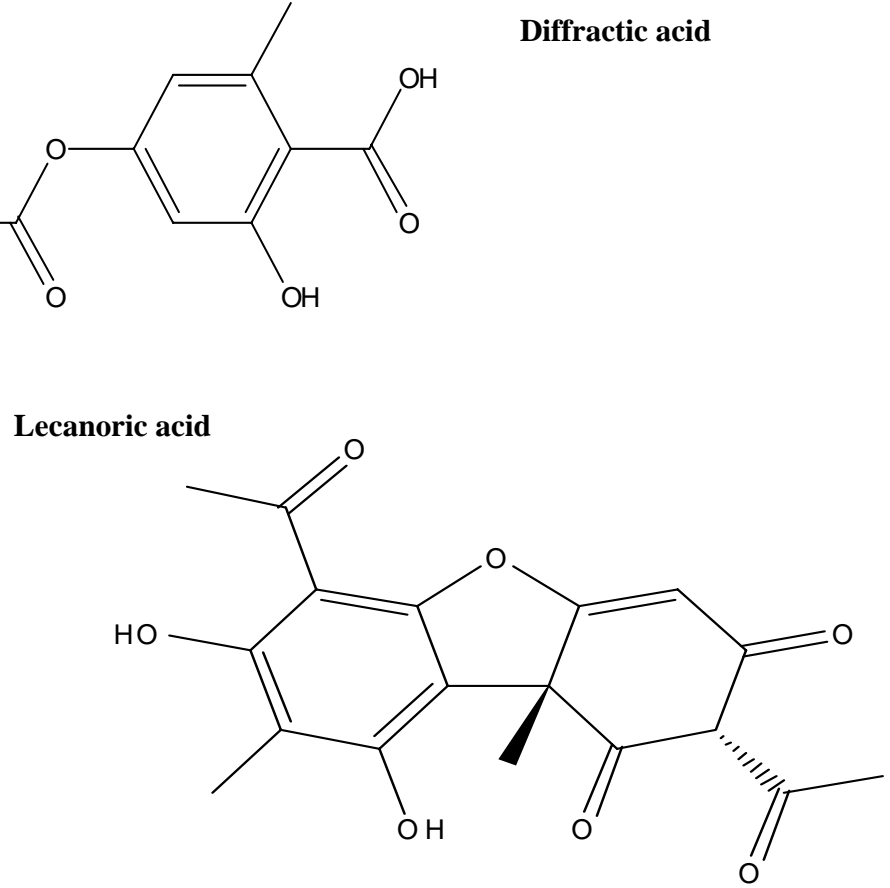

Usnic acid

Figure 1. Planar structure of lichen metabolites. 


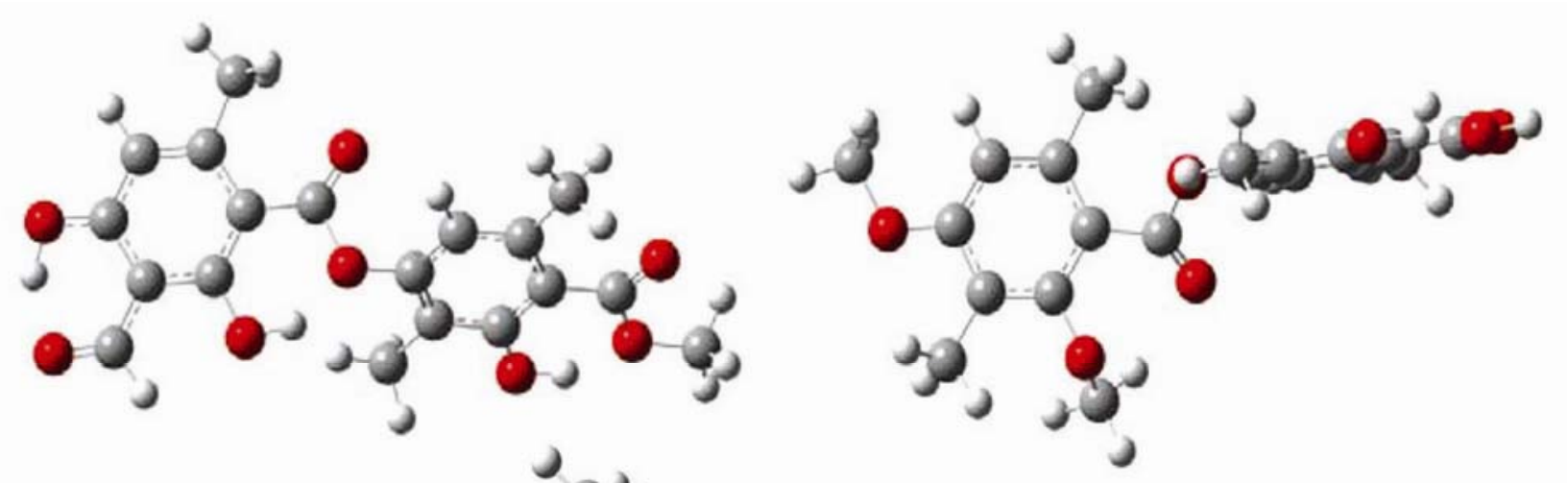

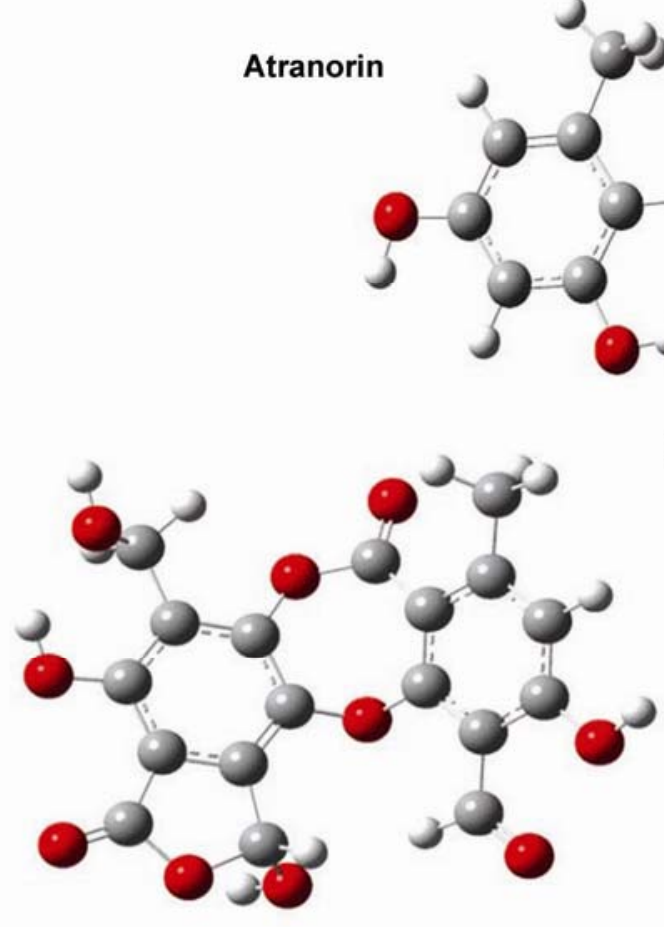

Salazinic acid
Diffractic acid

Figure 2. Three dimensional optimized (B3LYP/Midix) structure of lichen metabolites.

Protein-ligand docking: The docking of the target protein with the ligand was performed using the AutoDock vina (Trott and Olson, 2010) in PyRx platform. Docking was performed to obtain a population of possible conformations and orientations for the ligand at the binding site. Using PyRx software, the macromolecule (COX-2) and ligands are prepared and then docking was performed using a grid whose centers are 34.8544, -29.0810, -9.1090 and dimensions are 25.00, 25.00, 25.00
Angstrom. Throughout the docking study the macromolecule was kept as rigid and ligand molecules were flexible. The best conformation was chosen with the lowest docked energy or binding affinity pose, after the docking search was completed. The interactions of complex protein-ligand conformations, including hydrogen bonds and the bond lengths were analyzed by using PyMOL (Figure 3). 

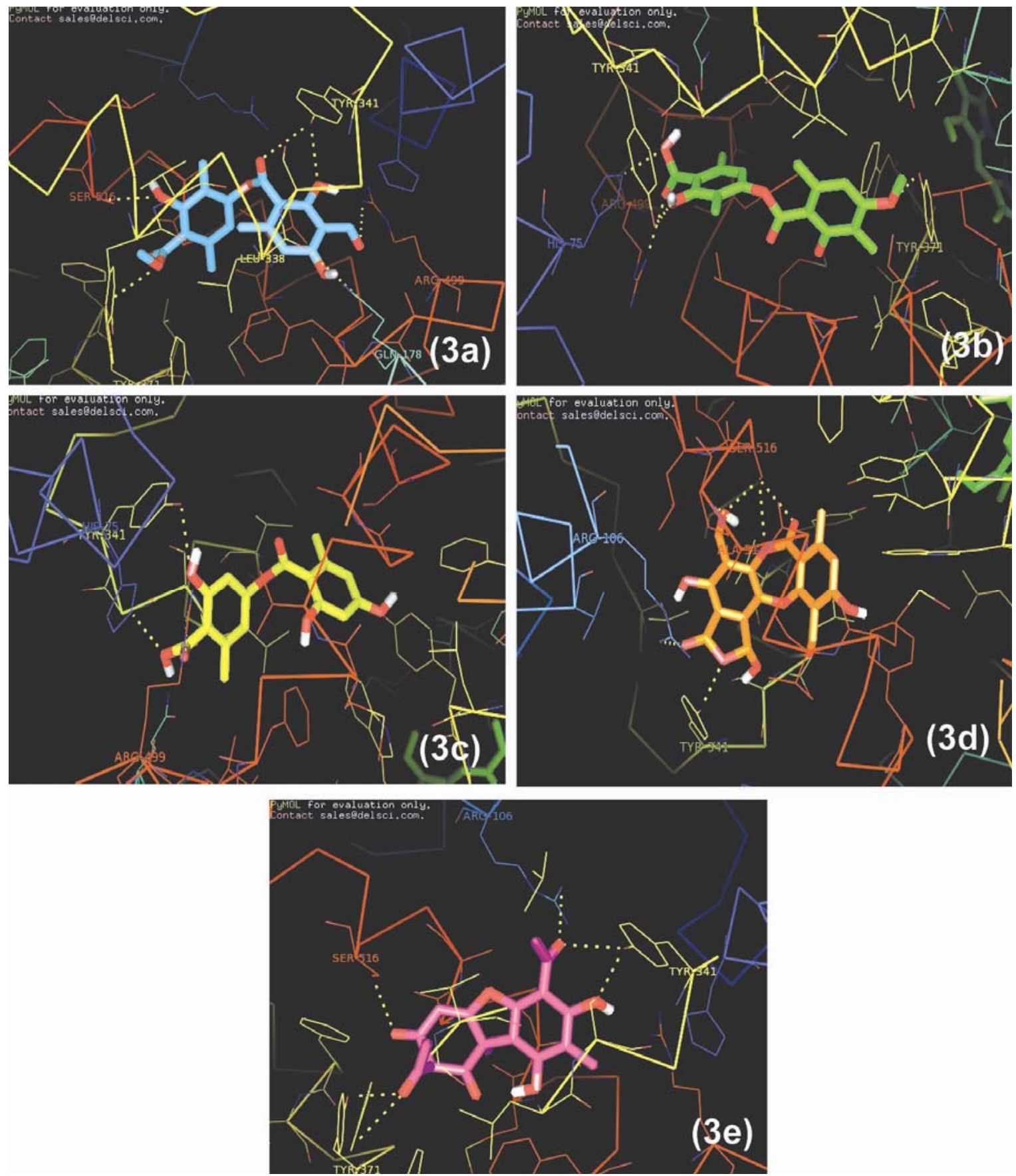

Figure 3. Binding mode of Atranorin (3a), Diffractic acid (3b), Lecanoric acid (3c), Salazinic acid (3d) and Usnic acid (3e) with cyclooxygenase-2 enzyme, yellow dots (-------) indicates $\mathrm{H}$ bonding.

Before screening the ligands, the docking protocol was validated by redocking celecoxib ligand into its binding pocket within the COX-2 crystal structure to obtain the docked pose and RMSD. The result showed that the optimized celecoxib almost exactly superimposed with the experimental crystal structure of celecoxib (Figure 4). Thus, the protocol is good in reproducing the X-ray crystal structure and can be applied for further docking experiments. 


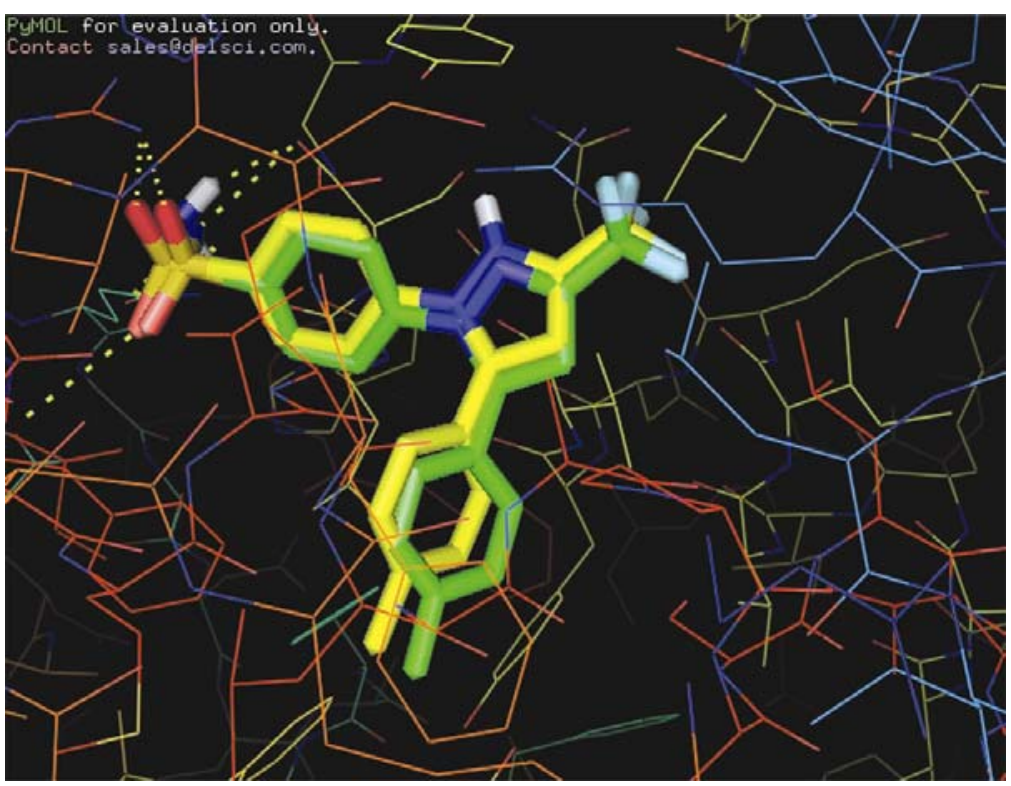

Figure 3. The superimposition of the best docking structure of Celecoxib with the X-ray structure.

( $\square$ ) Docked Celecoxib, ( $\square$ ) Experimental Celecoxib, yellow dots (-------) indicates H bonding.

Lipinski's rule of 5 screening: Lipinski's rule of 5 is widely implemented to analyze the "druglikeness" of the proposed ligand. It states that poor absorption or permeation is more likely when a ligand molecule violates these rules (Lipinski et al., 2001). The properties of the ligands are calculated for the screening using Chemaxon's MarvinSketch software 15.6.29.

\section{Result and Discussion}

Molecular docking studies of five lichen metabolites namely usnic acid, atranorin, diffractic acid, lecanoric acid and salazinic acid were carried out with COX-2 enzyme using AutoDock Vina, to identify the binding mode of ligands and the intermolecular hydrogen bond interaction between ligands and the target protein. Among all the docked ligands, the lecanoric acid satisfied the Lipinski's rule of 5 and exhibited best binding affinity (-9.83 $\mathrm{kcal} / \mathrm{mol}$ ) which was comparable to the reference ligands celecoxib (-12.3 kcal/mol) and rofecoxib (-11.2 kcal/mol). Although atranorin and diffractic acid showed good binding affinity $(-8.7 \mathrm{kcal} / \mathrm{mol}$ and $-8.6 \mathrm{kcal} / \mathrm{mol}$, respectively) but they failed to satisfy the Lipinski's rule of 5. On the other hand, the salazinic acid and usnic acid have shown binding affinity of $-7.9 \mathrm{kcal} / \mathrm{mol}$ and -4.7 $\mathrm{kcal} / \mathrm{mol}$, respectively and satisfied the Lipinski's rule of 5 (Table 1).

Cyclooxygenase plays a key role in the conversion of arachidonic acid to prostaglandins (Kurumbail et al., 1996). Prostaglandins regulate pathological processes such as inflammatory and cardiovascular responses (Smith et al., 1993). COX-1, a constitutive enzyme is present in mammalian cells and COX-2, an inducible enzyme is found in inflammatory sites (Howe et al., 200). Thus, suppressing levels of COX-2 will be an effective method for inhibiting inflammation. Currently, NSAID used widely to control inflammation, and it has been estimated that $30-60 \%$ of NSAID users have gastrointestinal side effects and abdominal discomfort (Mofleh and Rashed, 2007). The current study focuses on the in silico investigation of natural compounds from the lichen metabolites for anti-inflammatory property to avoid any undesirable side effects. From the results of our docking studies and the Lipinski's rule of 5 screenings, it can be concluded that the lecanoric acid and salazinic acid are potent COX-2 inhibitors which hold lots of promise to develop newer COX-2 inhibitors. 
Table 1. The ligand parameters to satisfy Lipinski’s rule of 5 and binding affinity (Kcal/mol) with Cyclooxygenase-2 (3LN1).

\begin{tabular}{|c|c|c|c|c|c|c|c|}
\hline $\begin{array}{l}\text { Compund } \\
\text { name }\end{array}$ & $\begin{array}{l}\text { Binding } \\
\text { affinity } \\
\text { (Kcal/mol) }\end{array}$ & Interacting residues of COX-2 & $\begin{array}{l}\text { Molecular } \\
\text { formula }\end{array}$ & $\begin{array}{c}\text { Molecular } \\
\text { weight } \\
(<500 \mathrm{Da})\end{array}$ & $\begin{array}{l}\log P \\
(<5)\end{array}$ & $\begin{array}{l}\text { H bond } \\
\text { donar (5) }\end{array}$ & $\begin{array}{c}\text { H bond } \\
\text { acceptor } \\
(<10)\end{array}$ \\
\hline Celecoxib & -12.3 & $\begin{array}{l}\text { GLN160, LEU320, SER321, } \\
\text { ARG481, PHE486 }\end{array}$ & $\mathrm{C}_{17} \mathrm{H}_{14} \mathrm{~F}_{3} \mathrm{~N}_{3} \mathrm{O}_{2} \mathrm{~S}$ & 381.08 & 4.0 & 1 & 3 \\
\hline Rofecoxib & -11.2 & HIS57, ARG481 & $\mathrm{C}_{17} \mathrm{H}_{14} \mathrm{O}_{4} \mathrm{~S}$ & 314.06 & 2.6 & 0 & 3 \\
\hline Atranorin & -8.7 & $\begin{array}{l}\text { GLN160, LEU320, TYR323, } \\
\text { TYR353, ARG481, SER498 }\end{array}$ & $\mathrm{C}_{19} \mathrm{H}_{18} \mathrm{O}_{8}$ & 374.35 & 6.6 & 3 & 6 \\
\hline $\begin{array}{l}\text { Diffractic } \\
\text { acid }\end{array}$ & -8.6 & $\begin{array}{l}\text { HIS57, TYR323, TYR353, } \\
\text { ARG481 }\end{array}$ & $\mathrm{C}_{20} \mathrm{H}_{22} \mathrm{O}_{7}$ & 374.14 & 5.4 & 2 & 6 \\
\hline $\begin{array}{l}\text { Lecanoric } \\
\text { acid }\end{array}$ & -9.1 & HIS57, TYR323, ARG481 & $\mathrm{C}_{16} \mathrm{H}_{14} \mathrm{O}_{7}$ & 318.07 & 4.7 & 4 & 6 \\
\hline $\begin{array}{l}\text { Salazinic } \\
\text { Acid }\end{array}$ & -7.9 & $\begin{array}{l}\text { ARG88, TYR323, ALA495, } \\
\text { SER498 }\end{array}$ & $\mathrm{C}_{18} \mathrm{H}_{12} \mathrm{O}_{10}$ & 388.04 & 2.3 & 4 & 7 \\
\hline Usnic acid & -4.7 & $\begin{array}{l}\text { ARG88, TYR316, TYR323, } \\
\text { TYR353, SER498 }\end{array}$ & $\mathrm{C}_{18} \mathrm{H}_{16} \mathrm{O}_{8}$ & 360.09 & 2.4 & 2 & 8 \\
\hline
\end{tabular}

\section{Conclusion}

The lichen metabolites showed better binding features with the COX-2 enzyme. Thus, these compounds can be effectively used as drugs for treating inflammation which is predicted on the basis of docking study. However, further investigations and in vivo studies are needed for the development of natural COX-2 inhibitors for the treatment of inflammatory disorders.

\section{Acknowledgements}

The authors wish to thank Mr. Mohammad A. Halim, Research Coordinator, Bangladesh Institute of Computational Chemistry and Biochemistry for his cordial support to conduct this study and State University of Bangladesh for providing Computational Lab facility.

\section{References}

Akhila, S., Aleykutty, N.A., Manju, P. 2012. Docking studies on Peperomia pellucida as antidiabetic drug. Int. J. Pharm. Pharm. Sci. 4, 76-77.

Al Mofleh, I.A and Al Rashed, R.S. 2007. Nonsteroidal, antiinflammatory drug induced gastrointestinal injuries and related adverse reactions: Epidemiology, pathogenesis and management. Saudi. J. Gastroenterol. 13, 107-13.

Eugenia, C., Pereira, S.C., Nascimento, R.C., Lima, N.H., Silva, A. F.M., Oliveira, E.B. Michele, B., Helene, B., Carlos,V. and Maria, E.L. 1994. Analysis of usneafasciata crude extracts with antineoplastic activity. Tokai J. Exp. Clin. Med. 19, 47-52.
Gaussian 09, Revision C.01, M. J. Frisch, G. W. Trucks, H. B. Schlegel, G. E. Scuseria, M. A. Robb, J. R. Cheeseman, G. Scalmani, V. Barone, B. Mennucci, G. A. Petersson, H. Nakatsuji, M. Caricato, X. Li, H. P. Hratchian, A. F. Izmaylov, J. Bloino, G. Zheng, J. L. Sonnenberg, M. Hada, M. Ehara, K. Toyota, R. Fukuda, J. Hasegawa, M. Ishida, T. Nakajima, Y. Honda, O. Kitao, H. Nakai, T. Vreven, J. A. Montgomery, Jr., J. E. Peralta, F. Ogliaro, M. Bearpark, J. J. Heyd, E. Brothers, K. N. Kudin, V. N. Staroverov, T. Keith, R. Kobayashi, J. Normand, K. Raghavachari, A. Rendell, J. C. Burant, S. S. Iyengar, J. Tomasi, M. Cossi, N. Rega, J. M. Millam, M. Klene, J. E. Knox, J. B. Cross, V. Bakken, C. Adamo, J. Jaramillo, R. Gomperts, R. E. Stratmann, O. Yazyev, A. J. Austin, R. Cammi, C. Pomelli, J. W. Ochterski, R. L. Martin, K. Morokuma, V. G. Zakrzewski, G. A. Voth, P. Salvador, J. J. Dannenberg, S. Dapprich, A. D. Daniels, O. Farkas, J. B. Foresman, J. V. Ortiz, J. Cioslowski, and D. J. Fox, Gaussian, Inc., Wallingford CT, 2010.

Howe, L.R., Subbaramaiah, K., Brown, A.M. and Dannenberg, A.J. 2001. Cyclooxygenase-2: A target for the prevention and treatment of breast cancer. Endocr. Relat. Cancer, 8, 97-114.

Kurumbail, R.G., Stevens, A.M., Gierse, J.K., McDonald, J.J., Stegeman, R.A., Pak, J.Y., Gildehaus, D., Miyashiro, J.M., Penning, T.D., Seibert, K., Isakson, P.C. and Stallings, W.C. 1996. Structural basis for selective inhibition of cyclooxygenase- 2 by anti-inflammatory agents. Nature $\mathbf{3 8 4}$, 644-8.

Kristmundsdottir, T., Jonsdottir, E., Ogmundsdottir, H.M. and Ingolfsdottir, K. 2005. Solubilization of poorly soluble lichen metaboli tes for biological testing on cell lines. Eur. J. Pharm. Sci. 24, 539-543. 
Lipinski, C.A., Lombardo, F., Doming, B.V., Feenay, P.J. 2001. Experimental and computational approaches to estimate solubility and permeability in drug discovery and development settings. Adv. Drug. Deliv. Rev. 46, 3-26

Oksanen, I. 2006. Ecological and biotechnological aspects of lichens. Appl. Microbiol. Biotechnol. 73, 723-734.

Okuyama, E., Umeyama, K., Yamazaki, M., Kinoshita Y and Yamamoto Y. 1995. Usnic acid and diffractic acid as analgesic and antipyretic components of Usnea diffracta. Planta Med. 61, 113-115.

Rashid, M.A., Bhuiyan, M.S.A., Hossain, M.A., Quader, M.A., Nutan, M.T.H. and Karim, M.R. 2001. (+)- Usnic acid, an antimicrobial agent from Permelia kamtschandalis. Pak. J. Microbiol. 1, 26-28.

Smith, C.J., Morrow, J.D., Roberts, L.J. and Marnett, L.J. 1993. Differentiation of monocytoid THP-1 cells with phorbol ester induces expression of prostaglandin endoperoxide synthase-1 (COX-1). Biochem. Biophys. Res. Commun. 192, 787-93.

Stocker-Worgotter, E. 2008. Metabolic diversity of lichenforming ascomycetous fungi: culturing, polyketide and shikimate metabolite production, and PKS genes. Nat. Prod. Rep. 25, 188-200.
Trott, O. and Olson, A.J. 2010. Software news and update AutoDock Vina: Improving the speed and accuracy of docking with a new scoring function, efficient optimization, and multithreading. J. Comput. Chem. 31, 455-46.

Vijayakumar, C.S., Viswanathan, S., Reddy, M.K., Parvathavarthini, S., Kundu, A.B., Sukumar, E. 2000. Antiinflammatory activity of (+) -usnic acid. Fitoterapia 71, 564-566

Vane, J.R., Bakhle, Y.S., Botting, R.M. 1998. Cyclooxygenases 1 and 2. Annual Rev. Pharmacol. Toxicol. 38, 97-120.

Wang, J.L., Limburg, D., Graneto, M.J., Springer, J., Hamper, J.R., Liao, S., Pawlitz, J.L., Kurumbail, R.G., Maziasz. T., Talley, J.J., Kiefer, J.R., Carter, J. 2010. The novel benzopyran class of selective cyclooxygenase- 2 inhibitors. Part 2: the second clinical candidate having a shorter and favorable human half-life. Bioorg. Med. Chem. Lett. 20, 7159-7163. 